\title{
PRESENTATION OF PSYCHIATRIC PATIENT IN ENT CLINIC WITH UNEXPLAINED SYMPTOMS.
}

\author{
1. MBBS, DLO, FCPS \\ Assistant Professor \\ Peoples University of Medical and \\ Health Sciences, Nawabshah. \\ 2. MBBS, DLO, MS \\ Associate Professor and Chairman \\ Peoples University of Medical and \\ Health Sciences, Nawabshah. \\ 3. MBBS, DLO, FCPS \\ Professor and Head \\ Peoples University of Medical and \\ Health sciences, Nawabshah. \\ 4. MBBS, DCN, FCPS \\ Assistant Professor \\ Peoples University of Medical and \\ Health Sciences, Nawabshah. \\ 5. MBBS, DLO, FCPS \\ Assistant Professor \\ Dow International Institute \\ 6. MBBS, DLO, FCPS \\ Assistant Professor \\ Dow University of Medical and \\ Health Sciences, Nawabshah.
}

Correspondence Address:

Dr. Dileep Kumar Khatri

Department of ENT

PMC Hospital, Nawabshah.

pilotmnivore@hotmail.com

Article received on:

23/08/2019

Accepted for publication:

23/11/2019

\author{
Dileep Kumar ${ }^{1}$, Muhammad Iqbal Rajput ${ }^{2}$, Noor Alam Ansari ${ }^{3}$, Moti Ram Bhatia ${ }^{4}$, Salman Niaz, \\ Irfan Ahmed Shaikh ${ }^{6}$
}

ABSTRACT... Objectives: It's very common that patients with psychiatric illness visit other specialties and in a survey it was found to hold a percentile of $15 \%$ to $30 \%$ of all primary care consultations. This study is designed to assess psychiatric patients who present in Clinic with ENT symptoms but result in no disease. Study Design: Cross-sectional study. Setting: ENT OPD of People Medical College, Nawabshah. Period: $1^{\text {ST }}$ Jan 2019 to $31^{\text {ST }}$ Jan 2019. Material \& Methods: We selected a total sample of 320 patients who presented with ENT diseases where we excluded patients with organic diseases and studied those who didn't show any clinical sign of organic diseases. The registered patients were evaluated by psychiatrist. Results: It was observed that out of 320 patients 180 patients were having psychiatric problem and those patients were advised to visit psychiatrist and take follow up on month end. Out of 180 patients 140 patients visited ENT OPD twice and 110 patients got relief in one visit. Conclusions: We found that conducting a cross-sectional survey using GHQ-12 helped us in detecting psychiatric patients presenting with unexplained diseases in ENT Clinics however to reach more accuracy in results, further tools can be utilized. We also believe doctors at all specialty clinics need to give more attention to their diagnosis and assist patients to open up to them and not to feel embarrassed.

Key words: $\quad$ Complications, Horizontal Incision, Septal Hematoma, SNOT-22, Vertical Incision.

Article Citation: Kumar D, Rajput MI, Ansari NA, Bhatia MR, Niaz S, Shaikh IA. Presentation of psychiatric patient in ENT Clinic With unexplained symptoms. Professional Med J 2020; 27(5):994-998. DOI: 10.29309/TPMJ/2020.27.05.4064

\section{INTRODUCTION}

As we see psychiatric illnesses are rising and offer a great challenge to all ranges of primary care and specialty medicine. Patients suffering from these diseases are estimated to fall around $15 \%$ to $30 \%$ of all primary care consultations. ${ }^{1}$

Where ENT disorders and patients psychology has been going together due to the increased awareness of diseases through internet which makes people anxious and worried. We encounter patients a lot of times who are over inquisitive on slight conditions say for instance postnasal discharge, stuffy nose or lump like feel in the throat. Clinical medicine applies general knowledge to some definite life conditions of a patient which however cannot be associated statically on a large scale. So physicians not only face some very clear limitations to diagnosis, rather they also feel anxious of the ambiguity that lies in some symptoms . Therefore it is advised to thoroughly understand and evaluate the case early and then apply any medical or surgical treatment.

However clinicians have come up with various methods in order to refract the threat to medical competence posed by such issues. So there is actually a very thin line between identifying a disease and call it unexplained or identify it as the psychological trait of the patient. According to WHO cross-National research, it was found that depression and anxiety has a very significant relation with somatic complaints around the globe. In our country approximately $3 / 4^{\text {th }}$ of the prevalent depression is due to the household income, poverty and other social security issues and its hardly taken care by the responsible authorities. And because these hospital and care clinics lack resources, patients tend to seek 
advice from practitioners of different specialties and many of them end up at ENT clinics as the most recurring of these diseases is head-aches, feeling of sensations, hissing noise in ears, thoracic pain, distress and other unexplainable fatigue and etc.

Speaking of these unexplainable cases, we should know that they are also termed as Somatoform and related disorders which stands for all such random thoughts, feelings and behaviors which do not necessarily give rise to a medical disease.

Although researches in this area have joined all such somatic complaints including depression, anxiety and hypochondriacally worries under one category of medically unexplained symptoms. ${ }^{2}$ To what extent a symptom is medically unexplained is difficult to evaluate as the only available tools are the probe flow sheet which doesn't give accurate results in cross-cultural studies.

Up to half of the patients visiting general medicine and surgical units suffer from symptoms that relate to psychological disturbances including stress and anxiety and researches in this area has long been started in order to find the relationship between psychiatric presentations in different clinics and physical diseases. In a study, the rise in tinnitus irritation is positively correlated with the level of depression in normal hearing patients. However it is still vague if ENT diseases cause more occurrences of mental health defects or co-occurring psychiatric disorders. It's been witnessed that Patients with common E.N.T diseases show more gloomy states of mind and also show psychiatric disorders more often. Some of the patients visiting ENT clinics suffer from cancer phobia and comforting them, often help in lessening the minor psychosomatic problems they are suffering. Various ENT conditions are strongly associated with psychology for instance cosmetic deformities of the face and specifically of the nose and their remedies, hearing damage, chronic pain, vertigo, tinnitus, Globus hysterics, hoarseness, choked feeling in the throat and headache. As a medical practitioner, every symptom in otorhinolaryngology should be evaluated while considering psychology as almost every ENT disease is more or less related to patient's psychology. Such patients should be thoroughly medically intervened as it's significant for both doctors and patients.

Since judgment is only based on surveys and questionnaires gathered by patient presentation and data recollection, it is of prime importance to stratify the number of such cases. In doing so we have funnel our study to only presentation of such patients who come to ENT clinics with such somatic complaints. Therefore to ensure proper management of these diseases the first step is to identify such patients.

\section{MATERIAL \& METHODS}

This cross-sectional study of 31 days was carried out in ENT OPD of people medical college Nawabshah from Jan $1^{\text {st }}, 2019$ to Jan $31^{\text {st }}, 2019$; which is extensively representative. We selected a total sample of 320 patients who presented with ENT diseases where we excluded patients with organic diseases and studied those who didn't show any clinical sign of organic diseases i.e. the ones who showed medically unexplained symptoms were evaluated by psychiatrist. The patients were interviewed from their time to admission by experienced investigating team. Our sample included ages from 20 to 60 of either gender of different levels of education; falling in graduate, above graduate, post graduate groups.

The exclusion criteria included the following

1. Patients suffering from organic diseases

2. Patients suffering from Coma or unable to speak

3. Drug addicts

4. Patients suffering from acute mental disorder

5. Patients whose vital organs suffered failure; for e.g. respiratory, cerebral hemorrhage, serious hepatic deficiency, acute diabetes with unstable blood sugar levels.

6. Patients admitted in Emergency ward

We used the Patients profile sheet (PPS) on registration to collect the socio-demographic details including gender, qualification, presenting complaints, period of visit, treatment history and diagnosis. We used the General Health 
Questionnaire GHQ-12 to confirm the mental health status of the patients. Patients were categorized on the basis of the questionnaire which involves 12 points in which the presence of 6 positive points and a score of 4 or above at the time of assessment confirms somatic disorder. We used SPSS version 20 for statistical analysis. The quantitative variables like age with its mean and standard deviation are also assessed. The qualitative variables like gender, marital status, and educational status were also assessed.

\section{RESULTS}

It was observed that out of 320 patients 212 patients were found to have somatic symptoms and a 108 showed scores below 4 in GHQ12. In this control group $47 \%$ were male and $53 \%$ were female. ${ }^{3}$

Overall the frequency of those who were married was the highest i.e. $80 \%$ while divorced and separated were $52 \%$ and only $8 \%$ were single. The mean age of patients diagnosed with MUS was 50 yrs vs $46 \mathrm{yrs}$ in patients with no MUS respectively. ${ }^{4}$ Further details to the education reveals $29 \%$ completed their matriculation while $64 \%$ had completed their masters and only $8 \%$ were undergraduates. Figure-1 shows the ENT Symptoms presented at the time of admission and their relation with GHQ12 positive and negative sores as observed in our study.

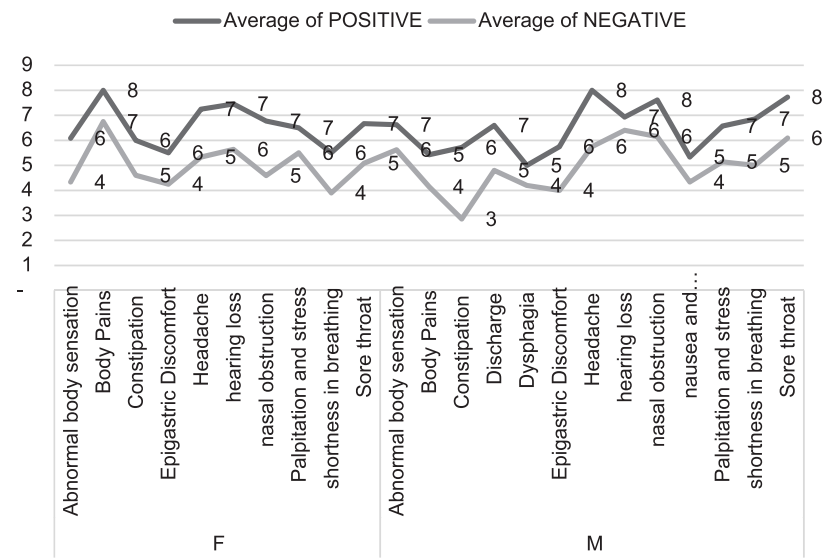

Figure-1. Patients with presenting ENT Symptoms and respective GHQ-12 Scores

Similarly Figure-2 shows the socio-demographic distribution of the patients scoring 4 or above and their presenting GHQ symptoms where significant number of patients suffered from hearing loss or nasal obstruction, Sore throat were $17 \%$ and $11 \%$ were cases with nausea and unresponsiveness was $1 \%$, Discharge 2\%, Dysphagia 3\%, Epigastric Discomfort 4\%, Body Pains 5\%, Palpitation and stress $5 \%$, Constipation $8 \%$, shortness in breathing $8 \%$, Abnormal body sensation9\% and Headache $9 \%$.

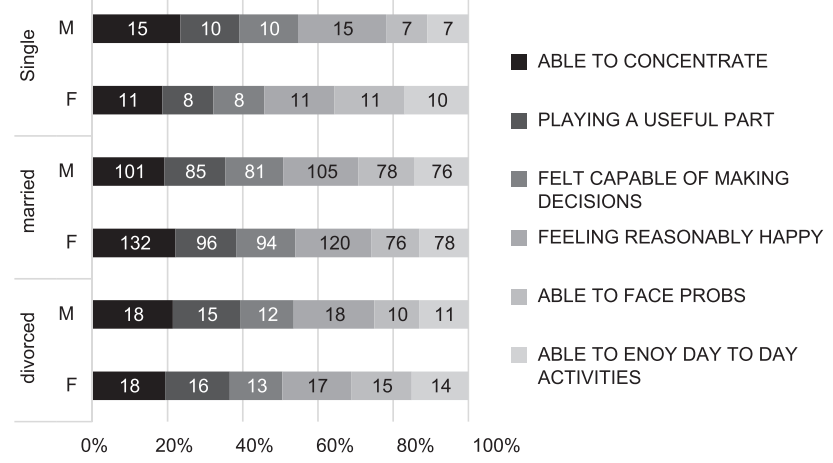

Figure-2. Socio-Demographic profile of patients with GHQ Score 4 or above

\section{DISCUSSION}

As discussed, there are several symptoms that cannot be medically identified at almost all care and specialty clinics.1 Even though studies signify that somatic disorders are common, yet the illness remains less recognized and its finding are seldom documented. We see a strong association of these medially unexplained symptoms with Psychiatric problems and almost all clinicians suffer in investigating such cases. An occurrence of comorbid depression has been estimated to be $40-66 \%$ and that of anxiety disorders to be $21-38 \%$. $^{6-7}$

Usually concentrating on the psychological and social factors that intensify symptoms can form a basis for behavioral medicine interventions that can improve results. Although this can also result in patients being socially stigmatized with unexplained symptoms. ${ }^{8,9}$ Such patients show higher deviation towards want to attention and emotional support. ${ }^{10}$

In our focused group we observe these patients being uncomfortable expressing their symptoms and being categorized with psychiatric label yet they would explain excessively details of their 
problems looking for validation from the clinician. In our study, we witnessed $66 \%$ of patients were found to have somatic symptoms out of a total of 320 patients and were positive for psychiatric illness. In a study conducted to find the relativity of somatic symptoms in patients with psychic issues revealed a positive value of $60 \% .{ }^{11}$

As per the quantitative statistics, our investigation showed these symptoms to be comparatively more in Female; they were $53 \%$ and in males it was $47 \%$ and the mean age was 50 years while in a relative study it was reported to be $46 \%$ which is close to our analysis. ${ }^{4,12}$ Amongst these $80 \%$ were married and were diagnosed with either body pains, bloating, hearing or breathing issues. Our study reported $9 \%$ presenting with headaches and $5 \%$ with body pains while in a previous study in a population of 50 patients $70 \%$ of patients were suffering with headaches. ${ }^{13}$ Similarly body pains and headaches in another such study was observed to be the most commonly occurring issue and around $59 \%$ in a sample of 80 people.

The number of psychiatric ailments has increased in the last few years in Pakistan and the reason is the inability of the physician to identify the nonpsychiatric complaints. ${ }^{14}$ Spitzer et al testified in $9-29 \%$ of their patients and a Dutch study stated around (22\%) of patients with somatoform disorder. ${ }^{15,16}$

Our results show that most of the patients suffered from these symptoms in their later stage as around $78 \%$ were above 40 in age. ${ }^{17}$ The average scores of patients in GHQ-12 is 12 which shows high severity of somatic disorders in contrast to the ones with explainable symptoms. Numerous researches have used GHQ-12 in detecting somatoform disorders and it has proven to be effective in specifying medically unexplained symptoms on a score of 4 or above. ${ }^{18}$ Although we still believe, a detail study should be carried out with a bigger number of population and not only in ENT but other specialty clinics in order to see the association of psychiatric disorders and somatic symptoms. Moreover clinicians should also schedule focused and time-bound appointments with such patients and more regularly in order to better understand their symptoms and proactively address to their issues. Also we believe our study had some inherent limitations as we could not carry an assertive sample size and getting in details of number of visits of such patients which might also help in deducing their disorder. And our medical professionals need to recognize and cater to the stigma attached to these psychiatric illness and run awareness campaigns in order for it to reduce the phenomenon. ${ }^{19-20}$ These are not just psychological processes but rather difficult biological phenomenon's and the existing management regulates both physical and psychological are not very effective and can only be conducted by appropriate professionals. We need to embrace a cross-cultural viewpoint in addressing psychosomatic questions which will benefit both basic knowledge and practical health care applications. ${ }^{21}$

Copyright $(23$ Nov, 2019.

\section{REFERENCES}

1. Kirmayer LJ, Groleau D, Looper KJ, Dao MD. Explaining medically unexplained symptoms. Can J Psychiatry. 2004; 49(10):663-672.

2. García-Campayo J, Lobo A, Pérez-Echeverría MJ, Campos R. Three forms of somatization presenting in primary care settings in Spain. J Nerv Ment Dis 1998; 186:554-60.

3. Ali A, Deuri SP, Deuri SK, Jahan M, Singh AR, Verma AN. Perceived social support and life satisfaction in persons with somatization disorder. Industrial psychiatry journal. $2010 \mathrm{Jul} ; 19(2): 115$.

4. Aamland A, Malterud K, Werner EL. Patients with persistent medically unexplained physical symptoms: a descriptive study from Norwegian general practice. BMC family practice. 2014 Dec;15(1):107.

5. Gerstenblith T, Kontas N. Somatic symptom disorders. In: Stern T, Fava M, Wilens T, eds. Massachusetts general hospital comprehensive clinical psychiatry. 2nd edn. 2015:255-64.

6. Deb KS, Balhara YP. Dhat syndrome: A review of the world literature. Indian J Psychol Med. 2013; 35:32631.

7. Grover S, Aneja J, Sharma A, Malhotra R, Varma S, Basu $D$, Avasthi A. Do the various categories of somatoform disorders differ from each other in symptom profile and psychological correlates. International Journal of Social Psychiatry. 2015 Mar;61(2):148-56. 
8. Looper KJ, Kirmayer LJ. Perceived stigma in functional somatic syndromes and comparable medical conditions. Journal of psychosomatic research. 2004 Oct 1;57(4):373-8.

9. Salmon P, Ring A, Humphris GM, Davies JC, Dowrick CF. Primary care consultations about medically unexplained symptoms: how do patients indicate what they want?. Journal of general internal medicine. 2009 Apr 1;24(4):450-6.

10. Salmon P, Ring A, Humphris GM, Davies JC, Dowrick CF. Primary care consultations about medically unexplained symptoms: how do patients indicate what they want?. Journal of general internal medicine. 2009 Apr 1;24(4):450-6.

11. Mumford DB, Tareen IA, Bhatti MR, Bajwa MA, Ayub $M$, Pervaiz T. An investigation of 'functional'somatic symptoms among patients attending hospital medical clinics in Pakistan-II. Using somatic symptoms to identify patients with psychiatric disorders. Journal of psychosomatic research. 1991; 35(2):257-64.

12. Haftgoli N, Favrat B, Verdon F, Vaucher P and Bischoff T. Patients presenting with somatic complaints in general practice: depression, anxiety and somatoform disorders are frequent and associated with psychosocial stressors. Family Practice 2010; 11(67): 1-8.

13. Khalid Hayat Khan, Mubashar Hussain Shah: Anxiety \& Depression; Comparative study of somatic symptoms between two population groups.

14. Khalily MT. Mental health problems in Pakistani society as a consequence of violence and trauma: a case for better integration of care. International journal of integrated care. 2011: 7; 11(4).1-7.
15. Spitzer RL, Williams JB, Kroenke K, Linzer M, deGruy FV, Hahn SR, et al. Utility of a new procedure for diagnosing mental disorders in primary care. The PRIME-MD 1000 study. JAMA. 1994, 272 (22): 17491756.

16. De Waal MW, Arnold IA, Eekhof JA, Van Hemert AM: Somatoform disorders in general practice: Prevalence, functional impairment and comorbidity with anxiety and depressive disorders. Br J Psychiatry. 2004, 184: 470-476. 10.1192/bjp.184.6.470.

17. Richardson RD, Engel Jr CC. Evaluation and management of medically unexplained physical symptoms. The neurologist. 2004 Jan 1;10(1):18-30.

18. Patel V, Araya R, Chowdhary N, King M, Kirkwood B, Nayak S, et al. Detecting common mental disorders in primary care in India: A comparison of five screening questionnaires. Psychol Med. 2008; 38:221-228.

19. Zoppei S, Lasalvia A. [Anti stigma campaigns: Really useful and effective? A critical review of the anti-stigma initiatives conducted in Italy. Rivista di psichiatria. 2010; 46(4):242-9.

20. Barke A, Nyarko S, Klecha D. The stigma of mental illness in Southern Ghana: Attitudes of the urban population and patients' views. Soc Psychiatry Psychiatr Epidemiol. 2011; 46(11):1191.

21. Al Busaidi, Z.Q., 2010. The concept of somatization: A cross-cultural perspective. Sultan Qaboos Univ. Med. J. $10,180-186$.

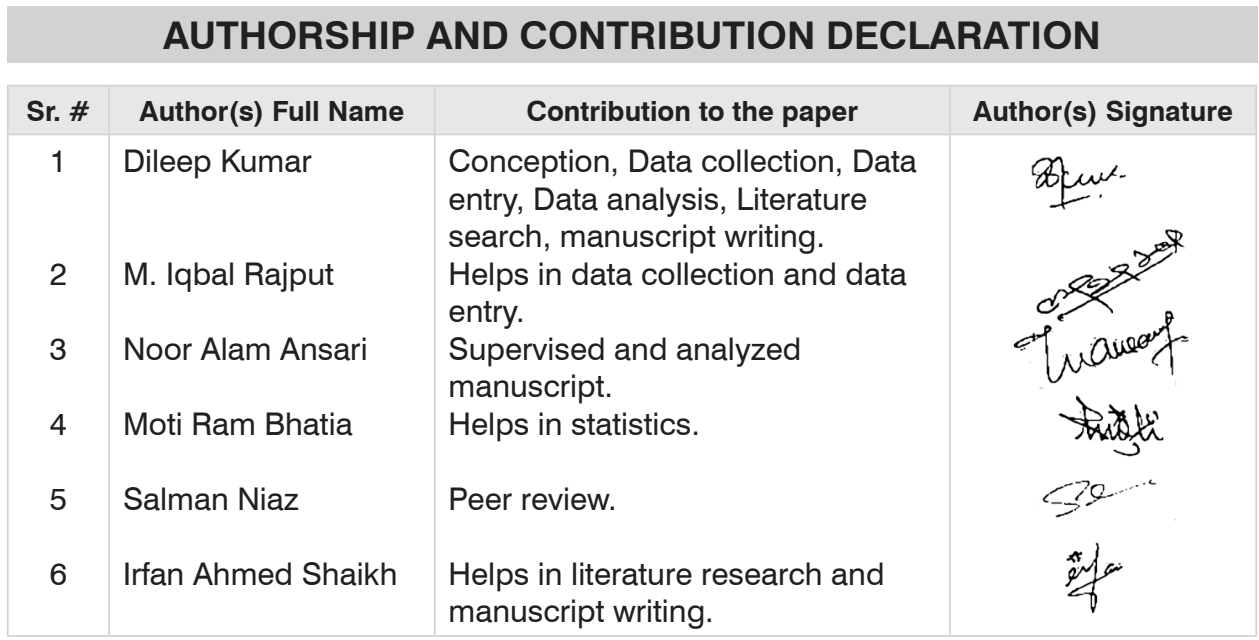

